\title{
The Epidemiology of Smear Positive Tuberculosis in Three TB/HIV High Burden Provinces of Kenya (2003-2009)
}

\author{
J. Sitienei, ${ }^{1}$ V. Nyambati, ${ }^{1}$ and P. Borus ${ }^{2}$ \\ ${ }^{1}$ Jomo Kenyatta University, Kenya \\ ${ }^{2}$ World Health Organization, Kenya Country Office, Kenya \\ Correspondence should be addressed to J. Sitienei; jsitienei@nltp.co.ke
}

Received 24 April 2013; Accepted 10 August 2013

Academic Editor: Suminori Kono

Copyright (c) 2013 J. Sitienei et al. This is an open access article distributed under the Creative Commons Attribution License, which permits unrestricted use, distribution, and reproduction in any medium, provided the original work is properly cited.

\begin{abstract}
Interest in epidemiology of tuberculosis in Sub-Sahara Africa has been activated by its reemergence in the mid-1990s because HIV and poverty have created a lethal combination that propagates TB transmission. Three provinces of Kenya that collectively contribute to about $56 \%$ of TB cases notified in Kenya were included in the study. Data for smear positive TB and TB HIV was extracted from existing database between 2003 and 2009. Data was analyzed to produce trends for each of the provinces, and descriptive statistics were calculated. To deduce existence of differences in gender, provinces, and years, analysis of variance was carried out with $P$ values and confidence intervals generated. There were more males (56\%) than females affected by TB, but more females with dual infection. Females have a bimodal peak in age groups 15-24 and 25-34, while males have one peak age group at 15-24. The rate of decline for males was higher than for females. Significant differences were found in gender $(P=0.001)$, year $(P=0.001)$, and rate of HIV positivity across the provinces $(P=0.001)$. Declining trend in cases is attributed to effects of integrating TB and HIV services and therefore programs need to address barriers to integrate care.
\end{abstract}

\section{Background}

Interest in the epidemiology of tuberculosis (TB) has recently been activated worldwide by its reemergence especially in Sub-Sahara Africa where the highest case notification rates have been reported. In 2010, Africa contributed $26 \%$ of the global burden with nine out of the 22 high burden countries contributing $81 \%$ of the global burden coming from Africa. During this time, Kenya was ranked position 10 amongst the high burden countries [1].

From mid-1980s, Sub-Saharan Africa experienced an upsurge in TB cases notified with the upsurge of incident cases being attributed primarily to HIV [2-4]. These countries are low income countries where HIV and poverty have created a lethal combination that propagates TB transmission [5]. Although it is challenging to accurately measure, much of the recorded increase may have actually reflected real changes in the incidence of tuberculosis in the community. Kenya had an average $10 \%$ increase in incident TB cases over the last decade before signs of decline began to be seen. The increase is likely to be due to several factors which have been influencing tuberculosis trends for many years. However, the main reason for the increase in tuberculosis has largely been attributed to HIV epidemic and to the growth of poverty in urban settings $[6,7]$. Over the years, TB disease seems to be getting more urbanized with time [7]. Development of active TB disease can be due to recently acquired infection or from reactivation of an infection acquired in the past. These patterns of the disease occur more frequently in persons infected with HIV [8]. While 10 percent of those infected with TB will progress to active disease over their life time, those who are coinfected with both TB and HIV on the other hand will progress to active TB more rapidly, at the rate of 10 per cent annually and about 60 per cent in their life time, increasing the numbers of people sick with TB [8].

The epidemiology of tuberculosis in Kenya has evolved over the years due to several factors including time, economic factors, environmental factors, and comprehensive control strategies that have been put in place since the National TB and Leprosy Program was launched by the Kenya government 
in 1980. The downward trend of cases notified in Kenya changed in early nineties when HIV came into the picture after the first case was diagnosed in the country in 1984. Since then, the number of HIV cases reported has continued to increase with a commensurate increase in TB cases notified. However, several control strategies in line with the WHO Stop TB strategy (DOTS) and TB HIV collaborative activities have been adopted and implemented at different levels shaping the trajectory that disease transmission took. The DOTS strategy was introduced in Kenya in 1993 as a pilot and quickly covered the whole country by 1997. In addition, TB HIV collaborative activities were introduced in the 3rd quarter of 2005 to specifically address issues of HIV coinfection.

Although there are recent indications that the cases notified in Kenya have stabilized and began to decline, about $56 \%$ of the cases reported still come from three out of 8 provinces in the country. Little work has been done in high burden provinces of Nairobi, Rift Valley, and Nyanza provinces of Kenya to understand the evolving epidemiology of tuberculosis epidemic, and the associated factors which can be addressed to mitigate the effect of TB.

\section{Study Area}

The study covered the western part of Kenya as shown in Figure 1.

Nairobi is the commercial and capital city of Kenya. Nairobi province covers an area of $6,966 \mathrm{~km}^{2}$ and has a population estimated to be 2,143,000 people according to the 1999 census. Nairobi has experienced one of the highest growth rates of any city in Africa. Since its foundation in 1899, Nairobi has grown to become the largest city in East Africa. The growth rate of Nairobi currently $6.9 \%$ has led to Nairobi's rapid expansion in population which is estimated to reach 5 million by 2015 . The rapid increase in population is mainly due to rural urban migration by young people in search for gainful employment. This has led to a rapid increase in informal settlements, some of which are the largest slums in Africa. Nairobi houses more than 102 slums scattered in the expanse of the city (DLTLD, 2008). More than half of the population in Nairobi live in slums which cover just $5 \%$ of the city area. In these informal settlements, people live in extreme poverty with most people making less than one US dollar a day. Since the dwellers are made of young people migrating with minimal skills, unemployment rates are high. Infection with HIV is common throughout the slums. In the Kenya aids indictor survey, report of 2007, the HIV sero prevalence in Nairobi province was $7 \%$. The HIV seroprevalence amongst TB patients notified in 2008 in Kenya was $44 \%$ after $88 \%$ of TB patients were tested for HIV (DLTLD, 2009).

Nyanza province of Kenya which covers the shores of Lake Victoria is one of Kenya's seven administrative provinces outside Nairobi. It is located in the southwest corner of Kenya. The province has a population of 4,392,196 (1999) within an area of $16,162 \mathrm{~km}^{2}$ [9]. The province supports some light industry and agricultural processing plants. The provincial capital, Kisumu, is the third largest city in Kenya. Infection with HIV is the single most important cause in the rise of tuberculosis cases notified in Nyanza province which has a general prevalence of HIV standing at $15.3 \%$. This is high and almost twice the national average 7.4\% [10]. The province notifies $20 \%$ of all TB cases in the country. This increase is probably related to the growing HIV epidemic. More than $75 \%$ of TB patients notified in Nyanza are dually infected with HIV (DLTLD, 2008). In addition, poverty levels in Nyanza stand at $64.6 \%$ [11].

Rift Valley province of Kenya is the largest province that stretches from Uganda to the west and from Tanzania to the south. The full economic potential of the Rift Valley region is, however, far from fully exploited, and the current growth in human resources and infrastructure development will ultimately have a major impact [9]. Majority of the people in the province live in rural areas, although urbanization is fast taking root with rural urban migration expected to increase. HIV sero prevalence remains lowest at $6.3 \%$ when compared to that of other provinces.

\section{Methods}

This study was conducted through extensive analysis of existing TB and TB/HIV data at the national TB control program databases. The national TB control program has a long history of collecting TB data through an elaborate and robust surveillance system that starts from the community. The program has adapted the recording and reporting tools from WHO for local use. Data collected from the community is aggregated at health facilities, then the district coordinator collects all data from reporting units which he aggregates before submitting to the Provincial Coordinator. The provincial coordinator aggregates the regional data before data is transmitted to the national level. At each of these levels, data is cleaned and validated. To ensure quality of the data collected, the DTLCs and PTLCs conduct routine monitoring missions to the relevant data collection levels where these data are verified and during quarterly meetings where each district $\mathrm{TB}$ coordinator presents their quarterly reports.

After retrospectively extracting new smear positive TB data at the national level for the three provinces for the years 2003 to 2009, the data was subjected to exploratory data analysis to look at trends inherent in the data. Data that did not have all required variables was dropped. The data was managed using Excel to create tables and graphs depicting trends and to allow comparison between provinces. Case notification rates were calculated (using the number of smear positive TB cases notified and population estimates from Kenya National Bureau of Statistics) and used to obtain trends of smear positive TB notification over the study period. The data was stratified based on sex and HIV status which was available from 2006 to 2009. TB diagnosis, treatment, and HIV testing during this period were done according to the national guidelines.

By policy, all presumed TB cases with signs and symptoms of TB are sent to the laboratory for collection of sputum specimen (morning and spot). After preparation of the specimen 


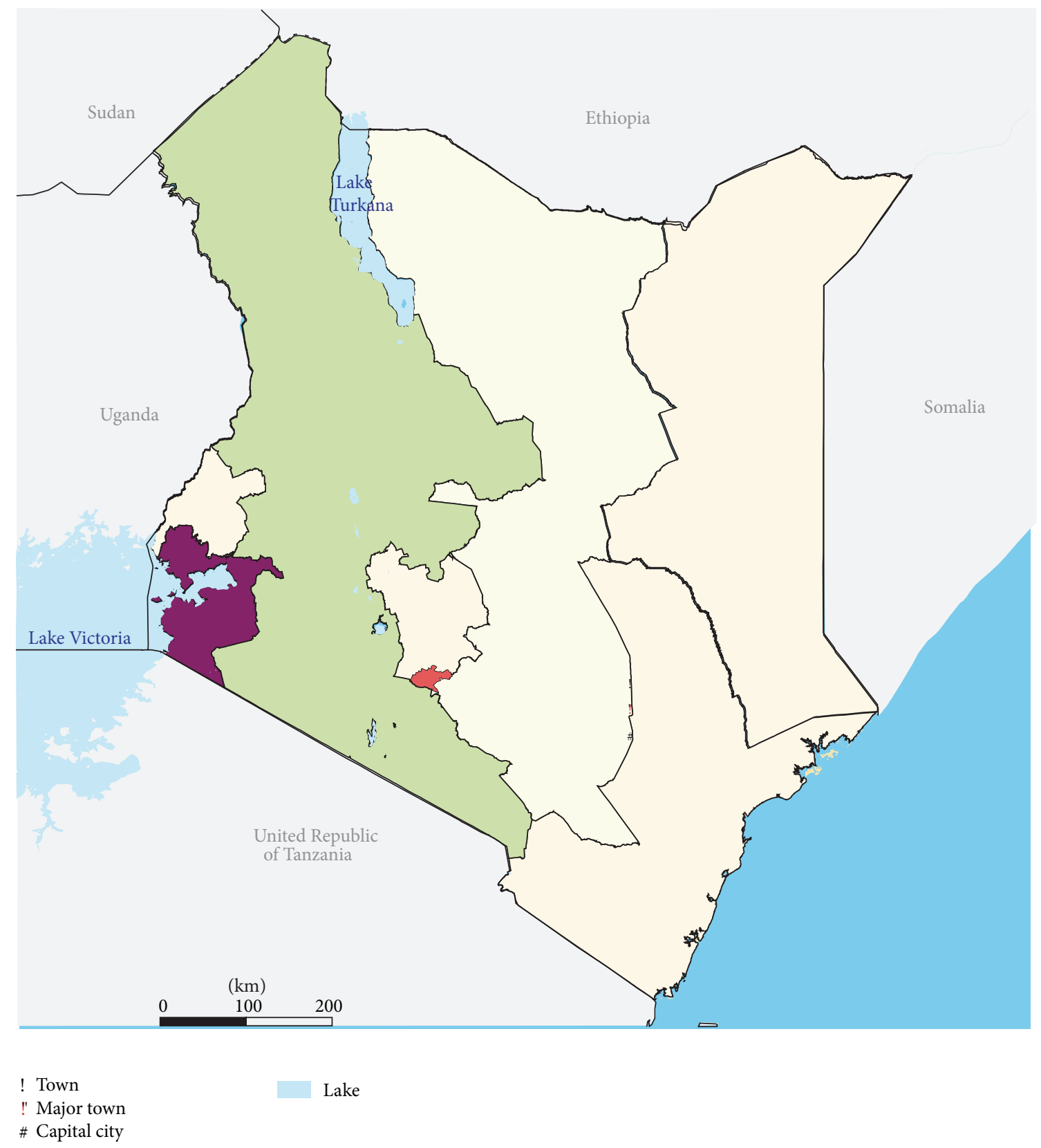

FIGURE 1: Map of Kenya showing location of study area.

and staining with Ziehl-Neelsen (ZN), the slides are read in the laboratory for presence or absence of tubercle bacilli. Those whose sputum turn out positive for tubercle bacilli are classified as smear positive. Before the patients are started on TB treatment, patients are provided with information and advantages of HIV testing. Blood specimen for rapid HIV testing is only collected after consent is provided by the patient. Commonly a finger prick is used to draw enough blood for Determine (Abbot) HIV 1 and 2 and SD Bioline HIV-1/2 v3.0 as serial tests, and if the results are inconclusive, Uni-Gold TM Recombigen HIV is used as a tie breaker. The blood results are kept confidential and used to make informed decisions on patient management.

\section{Results}

A total of 152, 406 smear positive TB cases notified between the years 2003 to 2009 were included in the review. Of these, there were $55.8 \%$ males and $44.2 \%$ females.

The peak age group for females over the years has consistently showed bimodal peaks at $15-24$ and $25-34$ years (Figure 2) giving a "stiletto shoe" appearance of the plotted trend over the years. This trend of distribution is different when compared to males in Figure 3 which shows that there has been a consistent peak in incident cases amongst males at age group 15-24. The highest peak was reached in 2005 in Nairobi. 


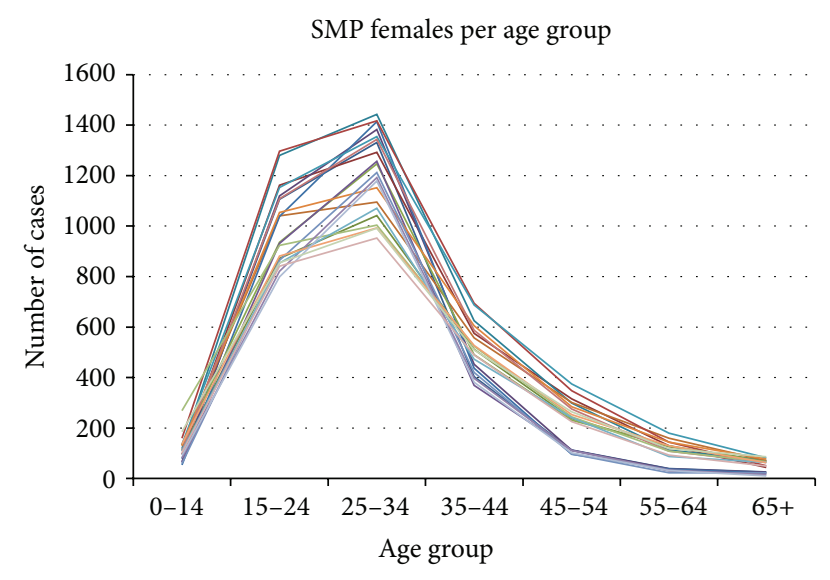

Figure 2: Distribution of females per age group.

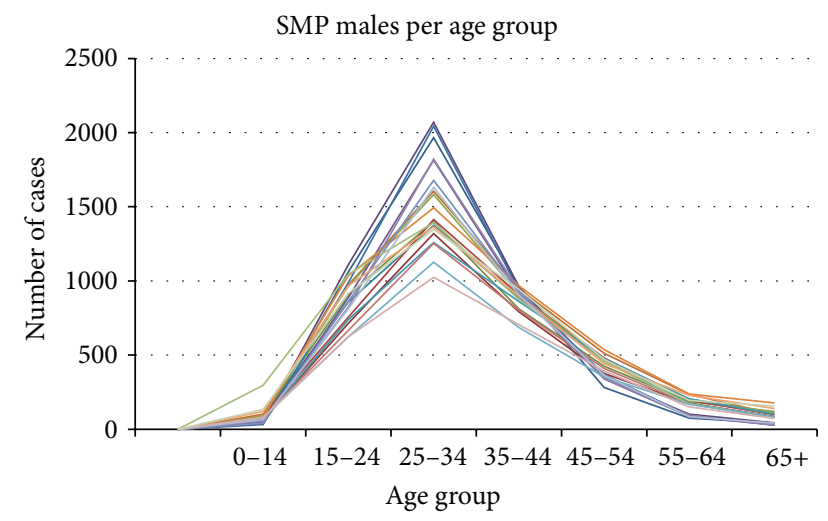

FigURE 3: Distribution of males per age group.

Figure 4 shows that the total notified cases in the three provinces in years 2003 to 2009 . The trend shows a gradual decline in notified TB cases (absolute numbers) from 2005 $(23,186)$ to 19,467 in 2009 . During this period, there was a decline of 3,719 cases reported (a decline of 16\%). Figure 5 shows the trend of smear positive TB cases notified by each of the provinces. Although Rift Valley province began with the least notified TB cases in 2003, the cases have generally increased to lead in 2006 and peak in 2007 before showing a sudden decline, although it remained higher amongst the three provinces. The trend for Nyanza province has been smooth peaking in 2005 and by 2007; Nyanza had the least notified TB cases amongst the three provinces.

The case notification rate per 100,000 population for the three provinces shows that the province with the highest notification rate was consistently Nairobi followed by Nyanza and Rift Valley, respectively (using projected population estimates from Kenya National Bureau of Statistics). It is notable that the peak was achieved in 2004 in all provinces followed by a gradual decline. The decline was highest in Nairobi followed by Nyanza and Rift Valley as shown in Figure 5.

Based on the case notification rates, there were more males with smear positive TB in Nairobi followed by Nyanza, and Rift Valley had the lowest case notification. Nairobi

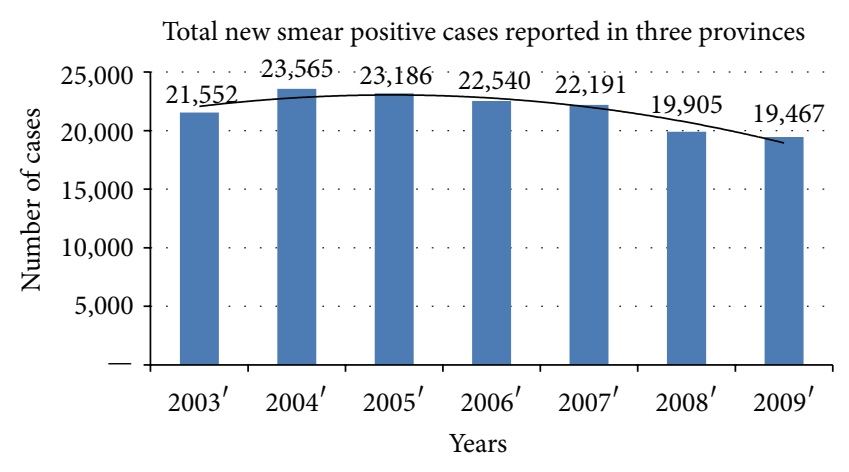

FIgURE 4: Trend of total smear positive TB cases.

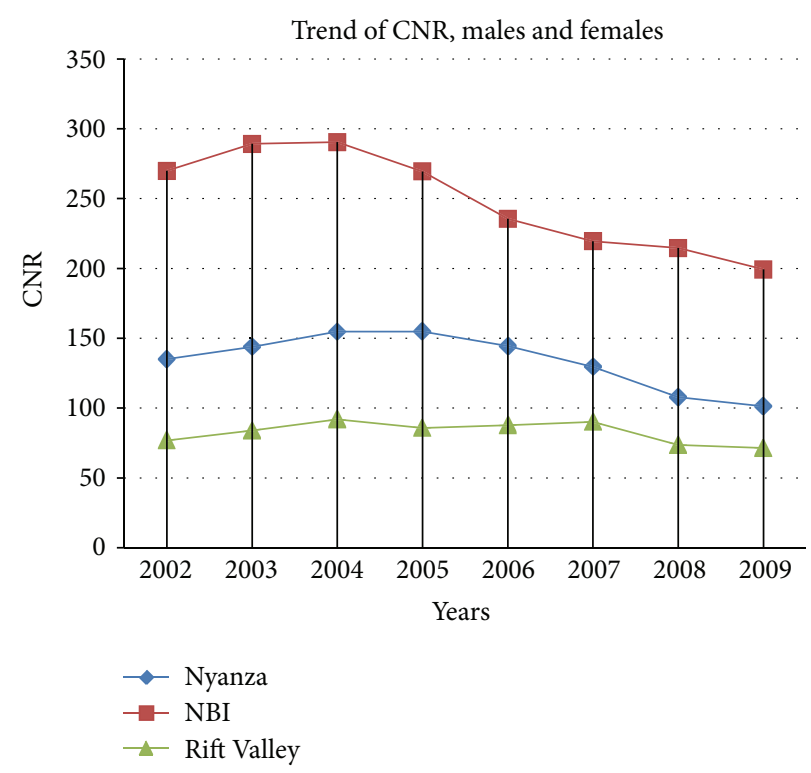

FIGURE 5: Case notification rates: 2003-2009.

province showed the highest decline followed by Nyanza, while Rift Valley showed a fairly stable trend. In all the provinces, there were more males with smear positive TB than females, although there was a small difference in Nyanza province, and the highest difference was seen in Nairobi province. In all the provinces, notification of smear positive TB cases amongst the females was on gradual decline from the highest in 2003 with the lowest in 2009.

Figures 6, 7, and 8 show the trends of HIV infection rates amongst TB patients in the three provinces: Nairobi, Nyanza, and Rift Valley, respectively, from 2005 when HIV testing amongst TB patients was started in Kenya upto 2009. As expected, the three figures show that female TB patients were more likely to be infected with HIV than males with the highest rates seen in Nyanza province. Although there has been progressive decline in HIV prevalence amongst tested TB patients in all provinces, the highest and fastest decline was seen in Rift Valley, followed by Nairobi. Nyanza province showed a stable HIV prevalence amongst male TB patients from 2003 to 2008 before a sudden decline. However, the decline in the prevalence was drastically affected amongst 


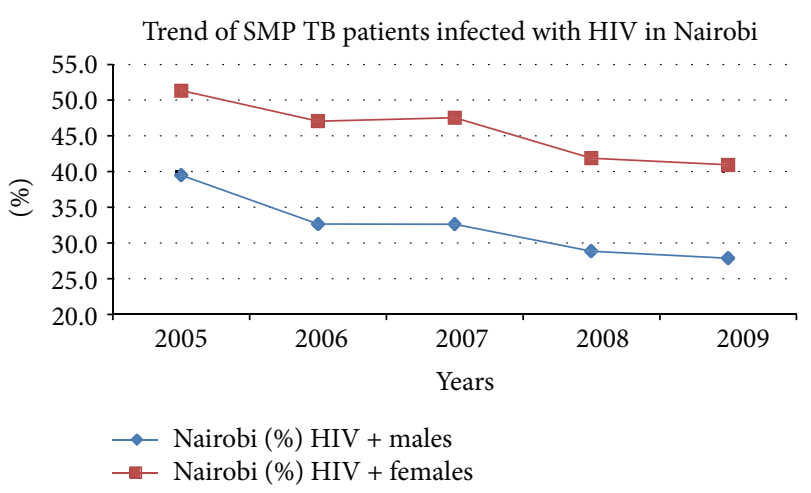

FIgure 6: Trend of HIV in Nairobi TB patients.

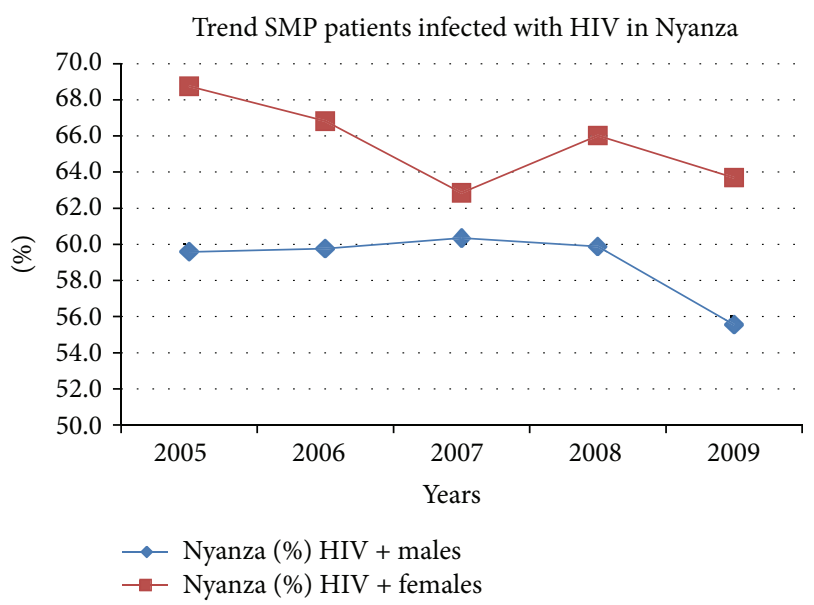

FIgure 7: Trend of HIV in Nyanza TB patients.

female patients of Nyanza in 2007 but much less in females in the other provinces.

It was found out that there was significant difference in HIV infection in gender $(P<0.001)$ and year $(P=$ $0.027)$. Furthermore, it was found that there was significant difference in HIV testing in gender $(P<0.001)$ and year $(P<0.001)$ but not provinces $(P=0.21)$. Additionally, it was found that there was significant differences in the proportions of HIV positivity amongst TB patients across the provinces $(P<0.001)$, gender $(P<0.001)$, and year $(P<0.001)$.

Over the years, the HIV seroprevalence in the general population from Kenya Aids Indicator Surveys (KAIS) of 2003 and 2007 showed that the Rift Valley had the lowest HIV infection followed by Nairobi with Nyanza province leading as shown in Table 1. There has been a decline in HIV sero prevalence in Nairobi $(0.7 \%)$ with Nyanza having a stable trend at around 15\%. Although Rift Valley has consistently the lowest HIV sero prevalence, there was an increase during this period. In the age group below 39 years in 2007, females were more likely to be infected with HIV than males, while males were sporadically more than females above this age group as shown in Figure 9. As for TB notification, there are more females affected than males below the age group of 14 , but thereafter, more males are affected than females.

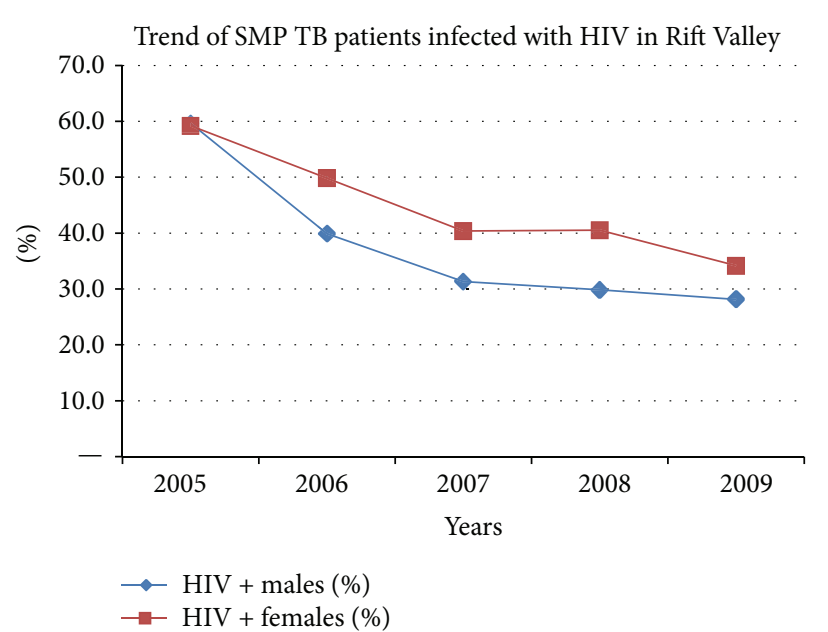

Figure 8: Trend of HIV in Rift Valley TB patients.

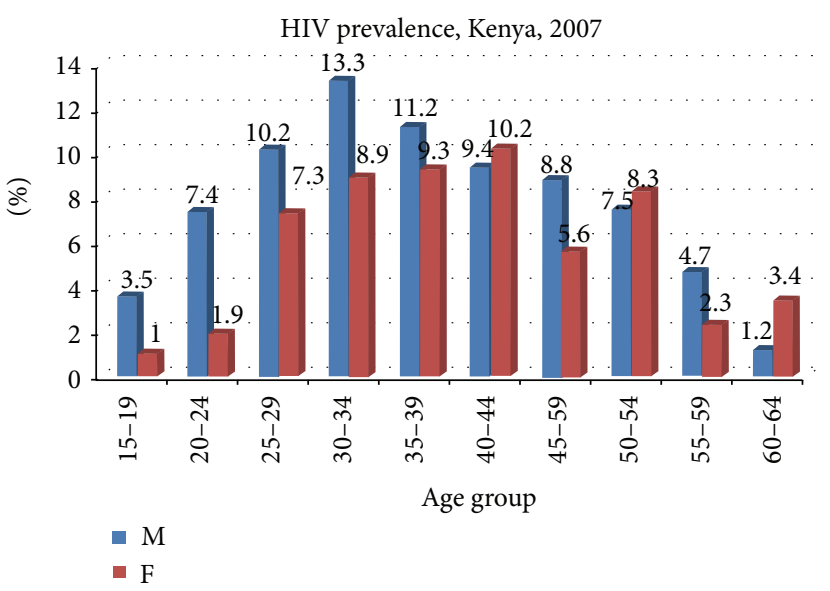

Figure 9: HIV prevalence in 2007.

TABLE 1: HIV sero prevalence (Kenya Aids Indicator Survey).

\begin{tabular}{lccc}
\hline Province & 2003 & 2007 & Change \\
\hline Nairobi & 9.9 & 9.2 & -0.7 \\
Nyanza & 15.1 & 15 & -0.1 \\
Rift Valley & 5.3 & 6.7 & +1.4 \\
\hline
\end{tabular}

This similarity may offer a plausible link between TB and HIV especially at lower age groups.

Figure 10 shows the trend of HIV sero prevalence in Kenya and all forms of TB cases notified from 1990 to 2010. The peak for HIV seroprevalence in the general population in Kenya peaked in 2000 at $13.9 \%$, while TB case notification peaked in 2007 at $289 / 100,000$ population respectively, giving a lag period of about 7 years for TB incidence to start to decline after the HIV decline.

\section{Discussion}

Notified TB cases in the three high burden provinces of Kenya have shown a steady decline in the last six years. Rift Valley 


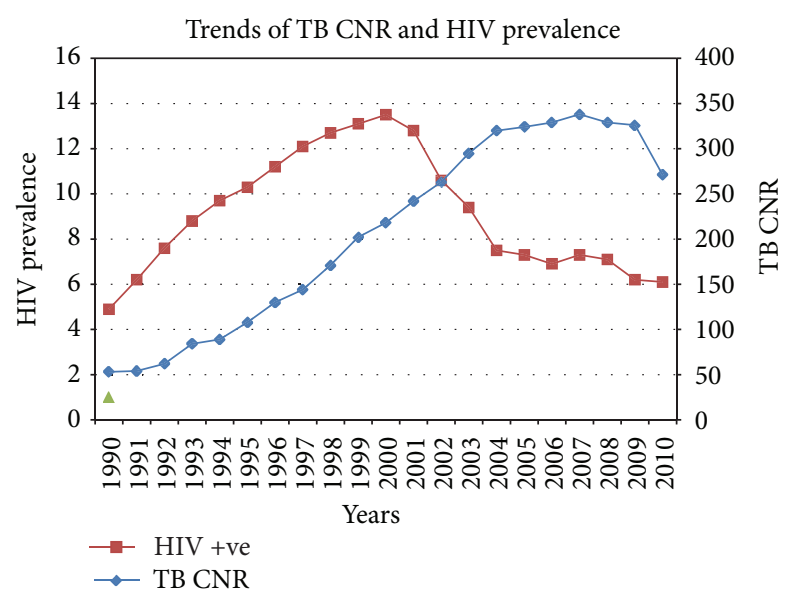

FIgURE 10: Trend of TB and HIV prevalence.

province consistently led in the absolute numbers that were reported to the national program followed by Nairobi and Nyanza provinces. This is based on the fact that Rift Valley is a vast province as this order is reversed when case notification rates are calculated and Nairobi leads followed by Nyanza and Rift valley, respectively. This is expected because Nairobi is basically an urban setting with a huge population living below poverty line. In aggregate, informal settlements occupy 5.84 per cent of all the land area of Nairobi that is used for residential purposes but houses 55 per cent of the city's population $[12,13]$.

Data available in the Ministry of Health indicate that prior to the increase in tuberculosis cases in Kenya, there had been a steady decline of cases notified till early 1990s when the trend began to reverse. This is closely associated with the history of HIV infection in Kenya where the first HIV case was reported in 1984 giving a lag period of about 6 years [14].

Through routine and other HIV surveillance methods, it has been demonstrated that HIV prevalence amongst TB patients in Africa is many times higher than that seen in the general population [8]. Further evidence has been adduced to demonstrate that African countries with the highest HIV prevalence rates are also those with a high rate of tuberculosis [9]. Moreover, linear relationship between HIV prevalence and TB notification rates demonstrates that rapid spread of HIV leads to an increasing burden of TB $[9,10]$. Consequently, spread of HIV is primarily responsible for driving the parallel epidemic of TB, often at a rate of 6 per cent per year [2].

The second national HIV population-based HIV prevalence survey in Kenya conducted in 2007 shows that $7.1 \%$ of the Kenyan adults aged 15-64 were infected with HIV. A significantly greater proportion of women $(8.4 \%)$ than men $(5.4 \%)$ were infected with HIV. More importantly, there was widespread variation in the HIV sero prevalence in the country with Nyanza leading with an average of $14.9 \%$ followed by Nairobi $8.8 \%$ and Rift Valley $6.3 \%$, and overall $6.7 \%$ of rural residents were infected with HIV compared to $8.4 \%$ urban residents with women having a significantly higher prevalence of HIV than men [10]. When compared to
2003 KDHS, the HIV prevalence in Nyanza remained similar (15.1\% versus $15.0 \%)$, Nairobi dropped marginally $(9.9 \%$ to 9.2\%) with an increase in Rift Valley (5.3\% to $6.7 \%)$. The HIV burden in Nairobi is further compounded by a high population which is poor and lives in squalid unplanned structures which propagates TB transmission.

In recognition of the role played by HIV in fuelling TB epidemic, Kenya adopted and started to implement the 12 collaborative TB/HIV activities in the third quarter of 2005 with the entry point being HIV testing amongst TB patients as stipulated in the interim policy on collaborative TB/HIV collaborative activities of 2004 by WHO [15]. This marked the beginning of provision of comprehensive care to dually infected $\mathrm{TB}$ patients and the recognition that failure to provide HIV testing and care for TB patients was considered substandard care. During the years (2005-2009), the two programs of TB and HIV which have and still remain partially vertical collaborated more and integrated HIV testing and ART services into TB settings within the context of counseling, consent, and confidentiality (3Cs). The impact of this intervention has a decline in deaths from TB from $14 \%$ in 2000 to $6 \%$ in 2010 [16]. Moreover, health education on HIV and prevention methods including provision of condoms within the TB clinics must have had generous impact on both HIV transmission and prevention within this critical population. In addition, introduction of collaborative activities created an avenue for the introduction of prevention with positives initiative which must have also largely contributed to decline in HIV sero prevalence and TB transmission. Consequently, the rate of decline is highest in Nyanza followed by Nairobi and Rift Valley which had the least rate. This is explained by the fact that the HIV interventions have been more pronounced and felt in areas with the highest rates of HIV.

This paper has demonstrated that TB incident cases in Kenya began to decline about 6 years after the decline of HIV prevalence. The peak prevalence for HIV was achieved in Kenya in 2000 at $13.4 \%$ which was followed by a gradual decline, while the TB incidence peaked in 2006. This decline is expected to continue as the effects of the interventions continue to bear more fruit as a clear demonstration of the effect of increased access to early ART initiation as well as improving program performance in other critical areas. Consequently, the steady decline of HIV prevalence amongst TB patients in Nyanza and Nairobi provinces could be attributed to steady expansion of ART services in these provinces and increased uptake on other prevention methods. Unfortunately, there is no data available or published from Kenya on the expansion of ART services in the three provinces. When Kenya initiated HIV testing amongst TB patients in the third quarter of 2005 , only $18 \%$ of all $\mathrm{TB}$ patients were tested for HIV. Subsequently, there was an accelerated HIV testing uptake to $86 \%$ in 2009 in the three provinces.

The fact that women bear the greatest brunt of the two diseases is demonstrated by a consistently higher infection rate of HIV amongst female TB patients and that the rate of decline is lower than that of males. The highest rate of HIV infection amongst females was found in Nyanza. There is a 
paradox though that despite females bearing the brunt of HIV infection, they seem to be marginally less affected by TB than males. In 2007, there was a temporary disruption of provision of care especially in Nyanza province, a relatively rural area following postelection violence which seems to have affected females more than males.

The bimodal peak age group in females of 15-24 and 2534 is different from the pattern seen in males which has a single peak at 25-34. There is no plausible explanation for this trend except a call for further investigation. This study did not address qualitative issues surrounding epidemiology of tuberculosis that is needed to further enrich this discussion. These areas would of necessity include the health seeking behavior of TB patients in the three provinces. This study suffered from the limitation inherent in dealing with data without linking that to personal characteristics like level of education. It is known that several other factors play different roles either alone or in combination to shape the epidemiology of smear positive TB cases notified. Notably, poverty directly accounts for almost one-third of the global burden of disease and leads to poor health, which in turn aggravates poverty and reduces human productivity. Ninetyfive per cent of TB cases and $98 \%$ of TB deaths are in developing countries [17]. The health seeking behavior of the poor is shaped largely by competing life priorities including deciding what is urgent between purchasing food and paying for health care. Additionally, the poor usually live in squalid environment that potentially exposes them to the risks of $\mathrm{TB}$ transmission.

\section{Conclusion}

Kenya's TB epidemic is currently at a critical point where downward trend of cases notified needs to be aggressively sustained so as to continue the dramatic reductions from incidence and TB deaths in line with the Millennium Development Goals. The fact that the disease pattern is changing especially in females where there is a clear epidemiologic shift in aging is a demonstration of reduced transmission to the younger age groups.

HIV remains the greatest challenge in the management of TB in similar settings especially because of the impact on mortality and other poor outcomes. The general impact of providing HIV care including provision of ART is likely to continue to reduce TB transmission and deaths. Promoting HIV testing amongst TB patients and increasing access to ART by all dually infected patients is a lifesaving strategy shown to yield fruits and should be encouraged.

TB prevention messages should be provided including providing isoniazid preventive therapy amongst HIV infected clients who do not have active TB. This will prevent infection ultimately leading to reduction in the pool of infectious cases.

Strong partnership between TB and HIV programs that promote joint policies on increased access to care has demonstrated that it can positively impact on the trend of transmission and the number of new cases notified. There is no doubt that strengthening patient and community partnerships to reduce stigma associated with the dual epidemic will be an added advantage so as to improve access to health facilities and care.

\section{References}

[1] WHO, Global Tuberculosis Control, 2011.

[2] E. L. Corbett, C. J. Watt, N. Walker et al., "The growing burden of tuberculosis: global trends and interactions with the HIV epidemic," Archives of Internal Medicine, vol. 163, no. 9, pp. 1009-1021, 2003.

[3] M. C. Raviglione, A. D. Harries, R. Msiska, D. Wilkinson, and P. Nunn, "Tuberculosis and HIV: current status in Africa," AIDS, vol. 11, pp. S115-123, 1997.

[4] M. F. Cantwell and N. J. Binkin, "Impact of HIV on tuberculosis in sub-Saharan Africa: a regional perspective," International Journal of Tuberculosis and Lung Disease, vol. 1, no. 3, pp. 205214, 1997.

[5] J. P. Narain, M. C. Raviglione, and A. Kochi, "HIV-associated tuberculosis in developing countries: epidemiology and strategies for prevention," Tubercle and Lung Disease, vol. 73, no. 6, pp. 311-321, 1992.

[6] S. Gillespie, S. Kadiyala, and R. Greener, "Is poverty or wealth driving HIV transmission?" AIDS, vol. 21, supplement 7, pp. S5S16, 2007.

[7] S. R. Benatar and R. Upshur, "Tuberculosis and poverty: what could (and should) be done?" International Journal of Tuberculosis and Lung Disease, vol. 14, no. 10, pp. 1215-1221, 2010.

[8] J. P. Narain and Y.-R. Lo, "Epidemiology of HIV-TB in asia," Indian Journal of Medical Research, vol. 120, no. 4, pp. 277-289, 2004.

[9] P. Godfrey-Faussett and H. Ayles, "Can we control tuberculosis in high HIV prevalence settings?” Tuberculosis, vol. 83, no. 1-3, pp. 68-76, 2003.

[10] S. Tripathy and J. P. Narain, "Tuberculosis and humanimmunodeficiency virus infection," in Tuberculosis, S. K. Sharma and A. Mohan, Eds., pp. 404-412, Jaypee Brothers Medical, New Delhi, India, 2001.

[11] GoK, Kenya Aids Indicator Surve, 2007.

[12] G. Alder, "Tackling poverty in Nairobi's informal settlements: developing an institutional strategy," Environment \& Urbanization, vol. 7, no. 2, pp. 85-107, 1995.

[13] M. Amuyunzu-Nyamongo and N. Taffa, "The triad of poverty, environment and child health in Nairobi informal settlements," Journal of Health \& Population in Developing Countries, 2004, http://www.jhpdc.unc.edu/.

[14] B. O. K'Oyugi and J. Muita, “The impact of a growing HIV/AIDS epidemic on the Kenyan children," in Aids, Public Policy and Child Well-Being, G. A. Cornia, Ed., 2002.

[15] WHO, Interim Policy on Collaborative TB/HIV Activities, WHO, Geneva, Switzerland, 2004.

[16] DLTLD, TB Annual Report, 2010.

[17] World Mapper, "A to Z index of maps," 2010, http://www .worldmapper.org/atozindex.html. 


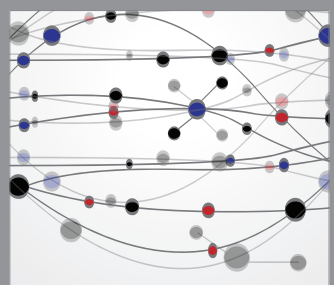

The Scientific World Journal
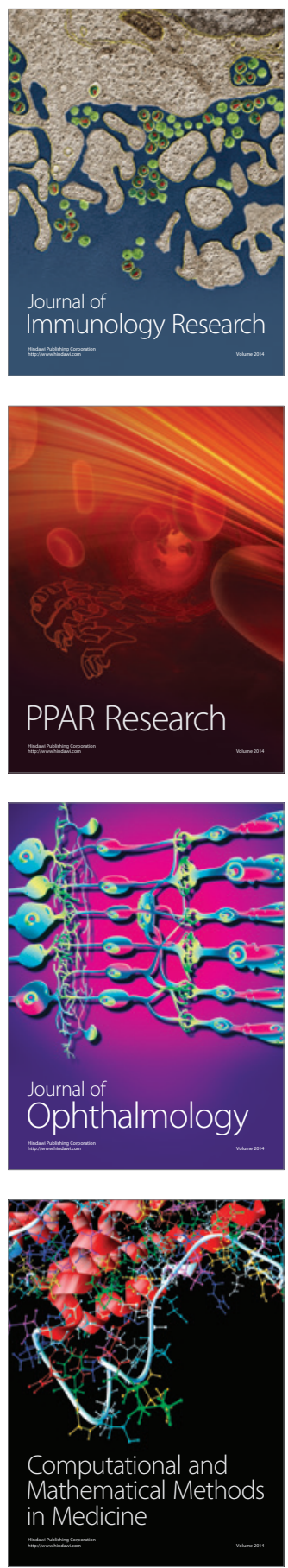

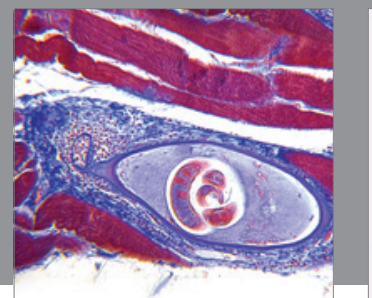

Gastroenterology

Research and Practice
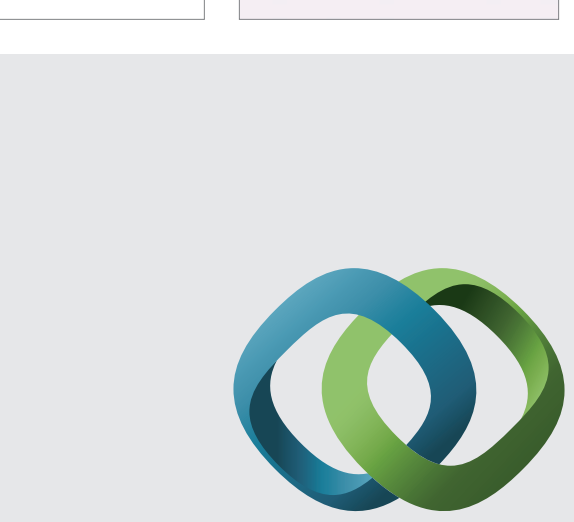

\section{Hindawi}

Submit your manuscripts at

http://www.hindawi.com
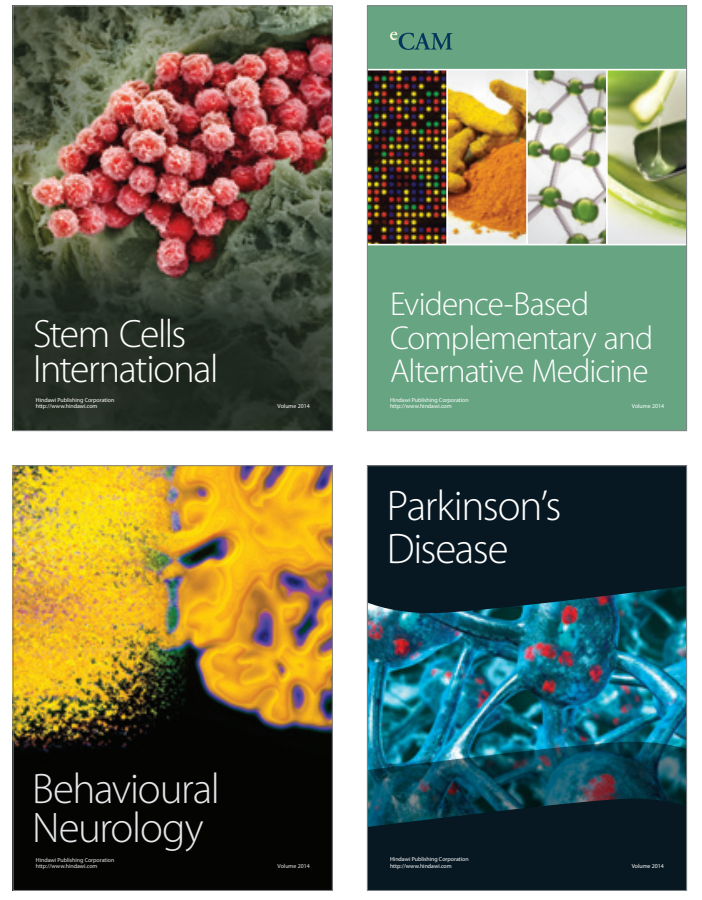
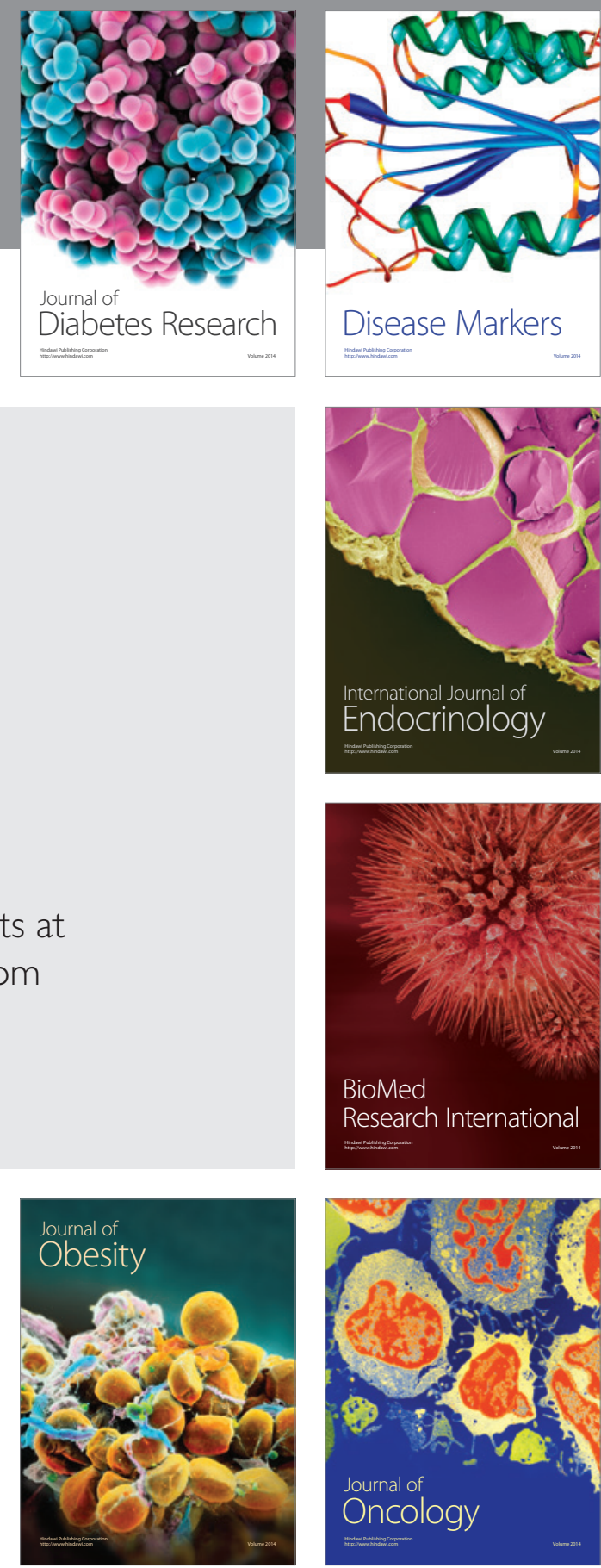

Disease Markers
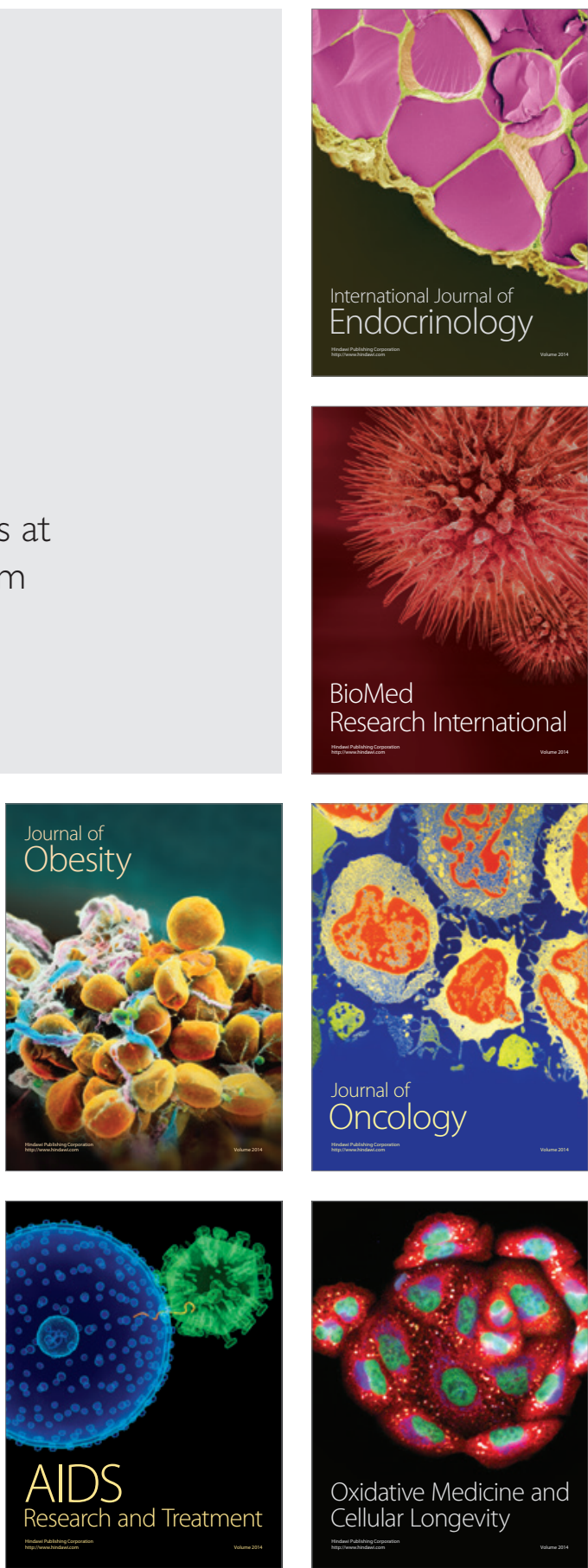